\title{
Crilvastatin 1R
}

National Cancer Institute

\section{Source}

National Cancer Institute. Crilvastatin 1R. NCI Thesaurus. Code C81159.

The 1R isomer of crilvastatin, a pyrrolidone non-competitive inhibitor of hydroxymethylglutaryl coenzyme A (HMG-CoA) reductase. 